
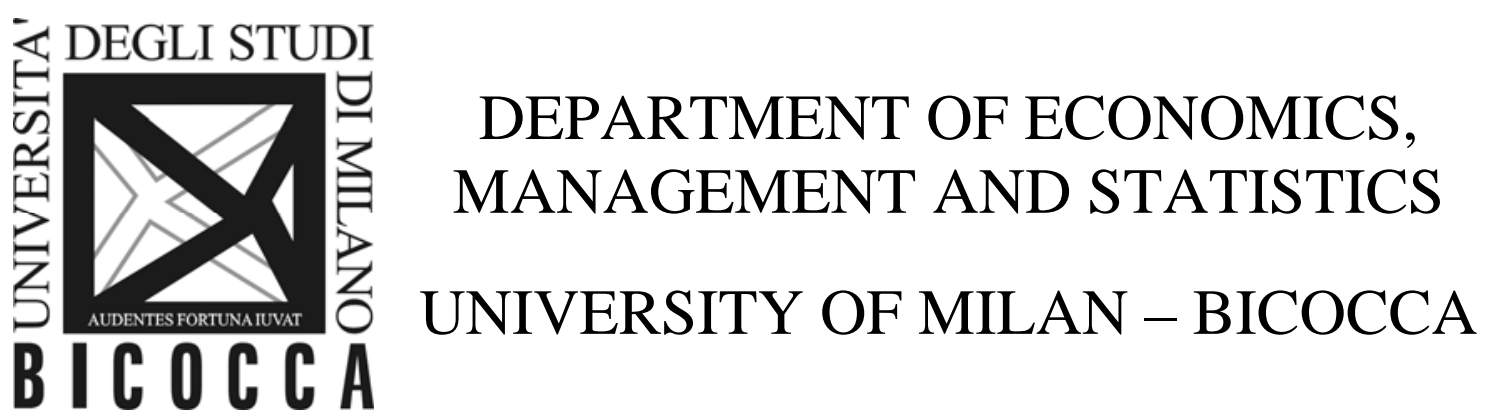

DEMS WORKING PAPER SERIES

\title{
The Effect of Particularism on Corruption: Theory and Empirical Evidence
}

\author{
Valentina Rotondi, Luca Stanca
}

No. 294 - February 2015

Dipartimento di Economia, Metodi Quantitativi e Strategie di Impresa

Università degli Studi di Milano - Bicocca

http://dems.unimib.it/ 


\title{
The Effect of Particularism on Corruption: Theory and Empirical Evidence
}

\author{
Valentina Rotondi* and Luca Stanca ${ }^{\dagger}$
}

February 20, 2015

\begin{abstract}
This paper investigates the role played by the cultural norms of particularism and universalism for collusive bribery. In our theoretical framework, the act of proposing or demanding a bribe violates a commonly held social norm, thus producing a psychological cost. By lowering this psychological cost, particularism increases the probability of offering or asking for a bribe. We test the predictions of the model by using individual-level data for 25 countries from the European Social Survey. Consistent with the theory, particularism is found to have a positive causal effect on the probability of offering a bribe, but no effect on the probability to be asked for a bribe. Overall, our findings indicate that policies aimed at favoring universalism may provide an effective tool in the fight against corruption.
\end{abstract}

Keywords: Corruption, Bribe, Particularism, Universalism.

JEL classification: D73, O17, C71, K42, Z13.

*Department of Economics, Catholic University of Milan, and LCSR, National Research University Higher School of Economics, Russian Federation. Largo Gemelli 1, 20126 Milan, Italy. E-mail: valentina.rotondi@unicatt.it

${ }^{\dagger}$ Corresponding author. Department of Economics and Neuro-Mi, University of Milan Bicocca, Piazza dell'Ateneo Nuovo 1, 20126 Milan, Italy. E-mail: luca.stanca@unimib.it 


\section{Introduction}

It is widely recognized that corruption has significant adverse effects on economic development and growth (Mauro, 1995, 1997), social equality (Gupta et al., 2002) and several other economic and social domains (Spector, 2005). As a consequence, the search for effective policies against corruption plays a key role in the agenda of policy makers throughout the world. However, despite a growing body of literature on corruption, a full understanding of its determinants is yet to come. This paper investigates, both theoretically and empirically, the role played by the cultural norm of particularism, as opposed to universalism, as a determinant of corruption at individual level.

A large number of studies has focused on the determinants of corruption at the macro level, showing that corruption is generally lower in countries characterized by centralized government, long lasting democracy and openmarket economy (Treisman, 2000), lower ethnic heterogeneity (La Porta et al., 1999), fiscal decentralization (Fisman and Gatti, 2002), higher share of Protestants (Treisman, 2000), free press (Brunetti and Weder, 2003) and higher share of women in government (Dollar et al., 2001, Swamy et al., 2001). ${ }^{1}$ These studies are generally based on cross-country aggregate data, and therefore do not address the role played by individual characteristics and context for the decision to engage in corruption.

With the recent availability of micro-level surveys that include specific questions on acts of corruption, such as offering or accepting bribes, a relatively smaller number of studies has turned to the determinants of corruption at individual level (e.g., Swamy et al., 2001, Torgler and Valev, 2006, Guerrero and Rodriguez-Oreggia, 2008, Mocan, 2008, Dong and Torgler, 2009, Torgler and Valev, 2010, Dong et al., 2012). Within this micro-level literature, most studies have focused on the monetary incentives and disincentives for engaging in corruption, despite the existence of a growing literature indicating that cultural factors also play an important role for economic behavior (e.g., Alesina and Glaeser, 2004, Fernandez and Fogli, 2009, Guiso et al., 2006).

Our paper contributes to the literature on the individual-level determinants of corruption by investigating the role played by the cultural norms of particularism and universalism. ${ }^{2}$ Parsons and Shils (1951) characterize the universalism-particularism continuum as a pattern of attitudes and behaviors typical of specific groups that, in turn, guide individual behavior. Universalism implies that correct behavior can always be defined and applied, irrespec-

\footnotetext{
${ }^{1}$ See Lambsdorff (2006) and Treisman (2007) for comprehensive reviews of this literature.

${ }^{2} \mathrm{~A}$ number of studies have shown that, at the aggregate level, national culture (i.e. Davis and Ruhe, 2003, Husted, 1999, Barr and Serra, 2010), religion and religiosity (La Porta, 1999, Treisman, 2000) and familistic values (Lipset and Lenz, 2000) are important determinants of corruption.
} 
tive of the context. Particularism, instead, implies that relationships come ahead of abstract social codes, so that norms and appropriate behavior are context-dependent. In universalistic societies, social relations mainly rely on weak ties and are informed by values related to power, achievement, and selfdirection. In particularistic societies, social relations rely on strong, cohesive group ties informed by principles of tradition, conformity, and benevolence (Uslaner, 2002).

While the attention for the effects of particularism and universalism is relatively recent in the economic literature, these cultural norms have been widely analyzed in sociology, where particularistic attitudes have been interpreted as conducive to lower civicness and higher prevalence of corruption (Lumby, 2006). Existing research suggests that closed and socially exclusive networks are a fertile ground for corruption (e.g., Lambsdorff, 2006, Lambsdorff et al., 2004, Tonoyan, 2003). This explanation, however, is theoretically underdeveloped, since the precise mechanisms underlying the causal link between particularism and corruption have not been fully understood.

In order to fill this gap, this paper develops and tests empirically a model of collusive bribery, focusing on the role played by the cultural norm of particularism. ${ }^{3}$ In our framework, the act of offering or demanding a bribe is perceived as inappropriate, according to a commonly held social norm, thus resulting in a psychological cost for the agents involved. We assume that this psychological cost is lower for particularistic individuals, who are relatively less reluctant to impose a burden on the society or to free-ride on others. As a consequence, ceteris paribus, particularism increases the probability of offering or asking for a bribe. We test the predictions of the model by using individual-level data for 25 countries from the European Social Survey. The findings indicate that, controlling for a wide set of individual characteristics, particularism increases the probability of offering a bribe, whereas it is not related to the probability of being asked for a bribe. This result is robust to alternative definitions of particularism, specifications of the model and econometric techniques that take into account the potential endogeneity of cultural norms. Overall, our findings indicate that there is a causal link between particularism and corruption at individual level. As a consequence, policies aimed at favoring universalism can provide an effective tool to reduce corruption.

The rest of the paper is organized as follows. Section 2 reviews the related literature. Section 3 presents the theoretical framework. Section 4 describes the data and methods. Section 5 presents the results. Section 6 concludes.

\footnotetext{
${ }^{3}$ Collusive bribery is defined as an illegal transaction that is beneficial to both the briber and the bribee, and is therefore particularly difficult to deter (Ryvkin and Serra, 2012).
} 


\section{Related Literature}

Our work contributes to the relatively small body of empirical literature on the determinants of corruption at individual level. Using micro-level data for 49 countries, Mocan (2008) finds that high-income individuals, males and people living in larger cities, are more likely to be asked for a bribe. At the country-level, the paper shows that the extent of corruption, as reported by citizens, is strongly correlated with indices of corruption perception. Guerrero and Rodriguez-Oreggia (2008) study the socio-demographic and institutional factors affecting corruption in Mexico, showing that weak enforcement of law, higher education and higher income levels are associated with a higher propensity to bribe. Tavits (2010) studies the relationship between the act of offering a bribe and its justifiability. Using original survey data for Estonia, she finds that both public officials and citizens are more likely to engage in corruption when they do not view corruption as wrong, and when they perceive that corrupt behavior is widespread among their peers. Lee and Guven (2013) use micro-level data from the European Social Survey to focus on masculinity, gender roles and risk preferences as cultural traits affecting the individual propensity to engage in corruption. Their results suggest that risk-seeking individuals are significantly more likely to offer and to be asked for a bribe, and that promoting gender equality might lead to less corruption. ${ }^{4}$

Another strand of related literature focuses on the determinants of justifiability of corruption at individual level. Swamy et al. (2001) study the relationship between gender and corruption. Based on World Values Surveys data for over 90,000 individuals in 49 countries, they find that women are significantly less likely to condone corruption. ${ }^{5}$ Torgler and Valev (2006) use World Values Survey and European Values Survey data to study the effect of age on the acceptability of corruption, finding a positive and significant effect of age, but no cohort effect. Dong and Torgler (2009) find that a higher level of political interest is associated with a lower acceptability of corruption and with a lower level of perceived corruption. Torgler and Valev (2010) investigate whether attitudes towards corruption and tax evasion vary systematically with gender and, more specifically, whether gender differences decrease as men and women face similar opportunities for illicit behavior. Their results indicate that aversion to corruption and tax evasion is significantly stronger for women.

A third strand of related literature investigates the relationship between

\footnotetext{
${ }^{4}$ Svensson (2003), using data on bribe payments of Ugandan firms, finds that the incidence of corruption can be explained by the variation in policies and regulations across industries. By combining data on corruption with financial information from the surveyed firms, he shows that firms' ability to pay and refusal power can explain a large part of the variation in bribes across graft-reporting firms.

${ }^{5}$ Using survey data for 350 Georgian firms, they also find that firms owned or managed by women are significantly less likely to be involved in bribing.
} 
social capital and corruption. The mechanism through which social capital may affect corruption is twofold. On the one hand, higher levels of social capital generally imply a stronger moral obligation for public officials to abstain from acting opportunistically. On the other hand, social capital may favor corruption, since belonging to a closed network reduces informational asymmetries, thus favoring collusive behavior. At the empirical level, high levels of interpersonal trust have been found to reduce corruption (e.g., Bjørnskov, 2006, La Porta et al., 1999, Uslaner, 2004), whereas high levels of bonding social capital (Putnam, 2000) are positively related to corruption, by leading those within a privileged network to feel that they can act illegally with impunity (Lipset and Lenz, 2000). Harris (2007) shows that indicators of strong ties, family orientations and particularized trust are significantly associated to higher levels of corruption. This suggests that the adverse effect on corruption is specific to generalized trust, as opposed to particularized trust (e.g., Warren, 2004, Uslaner, 2004).

The distinction between particularism and universalism thus plays a key role for understanding the determinants of corruption. While the sociological literature on particularism and corruption is well developed (e.g., Lambsdorff, 2006, Lambsdorff et al., 2004, Tonoyan, 2003), within economics there are only few papers investigating this relationship, mainly confined to the experimental setting (e.g., Fong and Luttmer, 2011, Eckel and Grossman, 2005). In a recent paper, De Blasio et al. (2014) show that three measures of particularism (in trusting behavior, political participation and associational activity) are positively related to each other and negatively related to several indicators of universalism. To the best of our knowledge, our work is the first to provide an economic analysis of the effects of particularism on corruption.

\section{Theory}

In our theoretical framework, corruption is viewed as the outcome of a social interaction, rather than contract design or information sharing (Chang and Lai, 2002). We consider a society in which risk neutral citizens and public officials meet randomly and interact for the provision of a good or a service. All agents have the option to engage in bribery with their transaction partner, provided that both parties accept the illegal transaction. Each agent can be either particularist or universalist. ${ }^{6}$ Each agent knows his own type, but does not know the type of his counterpart. Citizens are particularist with probability $\gamma$ and universalist with probability $1-\gamma$, while public officials are particularist with probability $\pi$ and universalist with probability $1-\pi$. Since all transactions involve a citizen and a public official, there are equal

\footnotetext{
${ }^{6}$ We make the assumption that the particularism vs. universalism continuum can be treated as a binary outcome for the sake of simplicity. The results obtained below are qualitatively unchanged under a more general specification.
} 
numbers of citizens and public officials in the economy and their populations are normalized to unity.

A social norm against corruption exists among both citizens and public officials, so that violating this norm implies a psychological cost. As in Akerlof (1980), this disutility depends not only on the individual's sensitivity to the norm, but also on his perceived level of widespread corruption. In particular, when corruption is low, the cost of violating the social norm is higher, so that individuals tend to engage less in corruption. On the other hand, when corruption is widespread, the cost of violating the social norm is lower and more individuals engage in corruption (e.g., Torgler, 2003). We assume that the disutility of corruption also depends on the perceived cost imposed by corruption on society. Particularists, characterized by limited morality as in Tabellini (2010), bear a lower cost, relative to universalists, when engaging in corruption. As a consequence, they are less reluctant to impose a burden on the society or to free-ride on others.

In order to prevent illegal transactions, the authority conducts random audits, so that agents engaging in corruption are jointly punished when discovered. The two agents engaging in corruption share the same probability of detection $(q)$ and penalty $(G)$. The timing of the corruption problem is described in Figure 1.

Figure 1: Corruption game tree

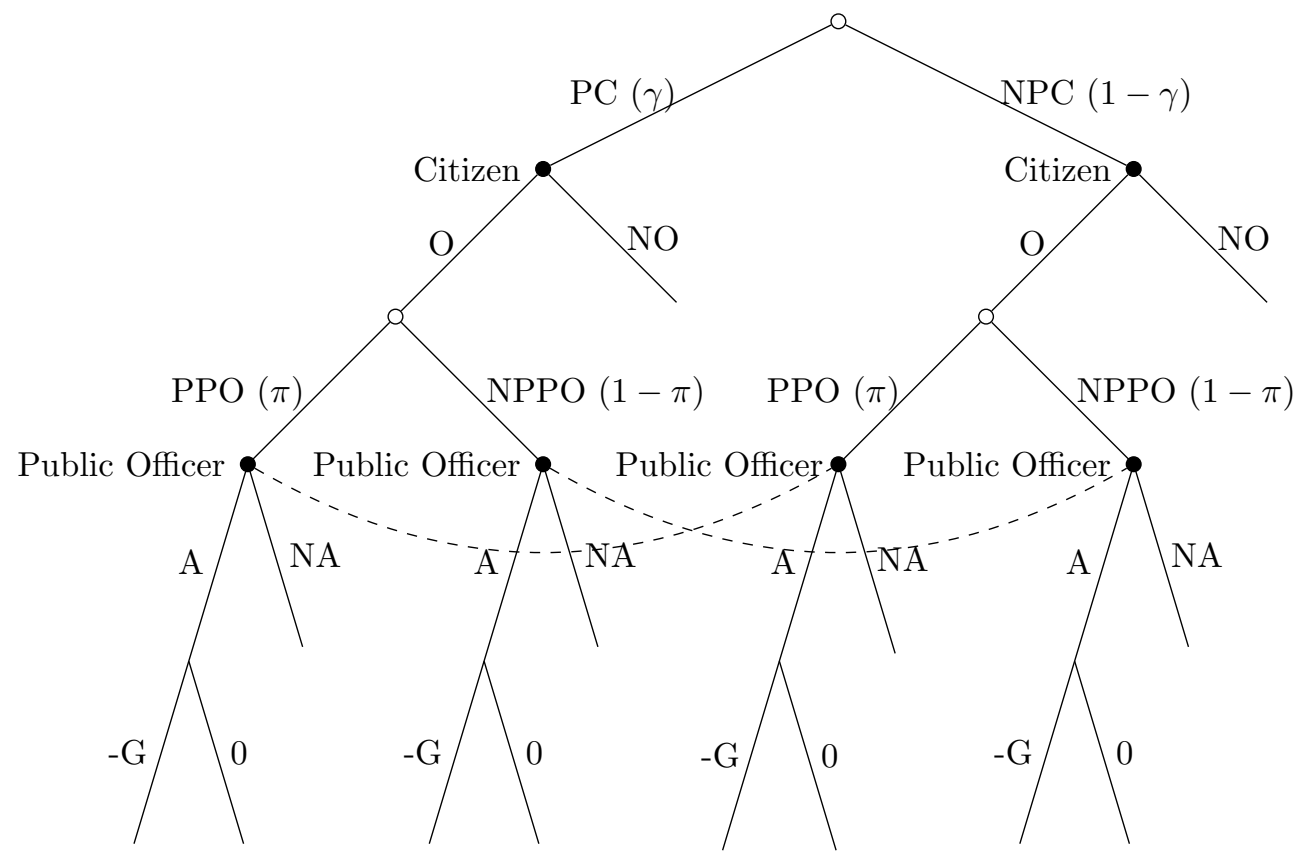

Note: $(\mathrm{N}) \mathrm{PC}=($ Non- $)$ Particularist citizen, $(\mathrm{N}) \mathrm{PPO}=($ Non- $)$ Particularist Public Officer, $(\mathrm{N}) \mathrm{O}=($ Does not) Offer bribe, $(\mathrm{N}) \mathrm{A}=($ Does not) Accept bribe. $\gamma=$ probability that Citizen is particularist, $\pi=$ probability that Public Officer is particularist, $\mathrm{G}=$ penalty if detected (with probability $q$ ). 
In the first stage, the citizen internalizes the possibility for collusion with the public official and evaluates the benefits and costs of corruption. If he chooses not to offer a bribe, then his payoff is $Y_{c}$, whereas if he chooses to offer a bribe his payoff depends on his own type, the choice made by the public official, and the probability of being discovered. If the public official accepts the bribe, the citizen's expected payoff is

$$
\begin{aligned}
& q\left(Y_{c}+K-C_{c}-B-G\right)+(1-q)\left(Y_{c}+K-C_{c}-B\right)= \\
& Y_{c}+K-C_{c}-B-q G
\end{aligned}
$$

where $Y_{c}$ is the citizen's initial endowment, $K$ is the gross gain from corruption and $B$ is the bribe amount paid to the public official. $C_{c}$ is the psychological cost of corruption defined as

$$
C_{c}=C_{c}(\mu, \theta, C)=\frac{\mu}{\theta} C
$$

where $\mu$ is the subjective sensitivity to the social norm. The density function of $\mu$, denoted by $f(\mu)$, is assumed to be uniform with support on $[0,1]$. The parameter $\theta$, with $0<\theta \leq 1$, denotes the perception of widespread corruption. $C$ is the perceived cost imposed by corruption on society. It is equal to $L$ if the citizen is particularist (with probability $\gamma$ ) and to $H$ if the citizen is universalist (with probability $1-\gamma$ ), with $L<H$.

If a citizen decides to offer a bribe and the public official does not accept, the citizen's payoff is $Y_{c}$. Given that the matching between a citizen and a public official is isolated and random, the probability of successful collusion faced by a citizen is given by the fraction of collaborative public officials, denoted with $\beta$. By internalizing this success rate in his decision, the citizen's expected payoff is:

$$
\Lambda=(1-\beta)\left(Y_{c}\right)+\beta\left(Y_{c}+K-C_{c}-B-q G\right)
$$

In the second stage, the public official decides whether or not to accept the citizen's proposal for collusion. If he refuses, then his payoff is $Y_{p}$, whereas if he accepts his payoff is

$$
\begin{aligned}
& q\left(Y_{P}+B-G-C_{p}\right)+(1-q)\left(Y_{P}+B-C_{p}\right)= \\
& Y_{p}+B-C_{p}-q G
\end{aligned}
$$

Thus, if the public official accepts, he will obtain the bribe $B$, but will also suffer a psychological cost $C_{p}$, arising from the violation of the social norm, where

$$
C_{p}=C_{p}(\varepsilon, \theta, C)=\frac{\varepsilon}{\theta} C
$$

As for the citizen's cost above, $C_{p}$ is assumed to depend on the individualspecific sensitivity to the social norm $(\varepsilon)$, uniformly distributed on $[0,1]$, the perception of widespread corruption $(\theta)$, and the perceived cost imposed by 
corruption on society $(C)$, that is $L$ for a particularist (with probability $\pi$ ) and $H$ for a universalist (with probability $1-\pi$ ).

In the third stage, the bribe amount $B$ is determined by bargaining between the public official and the citizen. ${ }^{7}$ The model can be solved backwards, starting from the bargaining game in the third stage.

\subsection{Bargaining Over the Bribe Amount}

In the last stage of the game, the size of the bribe $B$ is determined by Nash bargaining between the public official and the citizen. The amount of the bribe in equilibrium is therefore determined by maximizing the product of each player's gain from making a deal, with the bargain being feasible if and only if the net gain from bargaining is positive for each party:

$$
\begin{aligned}
\max _{B} & {\left[K-B-q G-C_{c}\right]\left[B-q G-C_{p}\right] } \\
& \text { subject to } \\
& K \geq B+q G+C_{c} \\
& B \geq q G+C_{p}
\end{aligned}
$$

The feasible bribery set is therefore

$$
q G+C_{p} \leq B \leq K-q G-C_{c}
$$

and the equilibrium bribe is

$$
B^{*}=B^{*}\left(K, C_{p}, C_{c}\right)=\frac{1}{2}\left[K-C_{c}+C_{p}\right]
$$

i.e.

$B^{*}=B^{*}(K, H, L, \gamma, \pi, \varepsilon, \mu)=\frac{1}{2}\left[K-\frac{\mu}{\theta}((1-\gamma) H+\gamma L)+\frac{\varepsilon}{\theta}((1-\pi) H+\pi L)\right]$.

From the expression above, $\frac{\partial B^{*}}{\partial C_{p}}>0$ indicates that the higher the cost for the public official of taking part in a corrupt transaction $\left(C_{p}\right)$, the larger the equilibrium bribe. $\frac{\partial B^{*}}{\partial K}>0$ shows that the higher the gain from corruption $(K)$, the higher the size of the bribe. Finally, the higher the psychological cost born by the corrupt citizen, the lower the size of the bribe $\left(\frac{\partial B^{*}}{\partial C_{c}}<0\right)$. Therefore, if the probability that the public official is particularist is high, the equilibrium bribe will be smaller $\left(\frac{\partial B^{*}}{\partial \pi}<0\right)$. On the other hand, if the probability that the citizen is particularist is high, the equilibrium bribe will be larger $\left(\frac{\partial B^{*}}{\partial \gamma}>0\right)$.

\footnotetext{
${ }^{7}$ Bribery is often the result of bargaining between public officials and clients (either firms or citizens). This explains the within-country and within-sector variation in both the frequency of corrupt transactions and the size of the bribes paid (Svensson, 2003).
} 


\subsection{The Public Official's Decision}

The public official is willing to collaborate with the corrupt citizen as long as:

$$
\pi\left(B-C_{p}-q G\right)+(1-\pi)\left(B-C_{p}-q G\right) \geq 0
$$

This expression indicates that the public official is corruptible if the net gain from corruption is positive, and therefore, given $C_{p}(\varepsilon, \theta, C)$, public officials with a lower value of $\varepsilon$ are more likely to accept bribes. The critical $\varepsilon^{*}$ which makes a public official indifferent between engaging in or abstaining from corruption is therefore:

$$
\varepsilon^{*}=\theta\left[\frac{K-2 q G-C_{c}}{(1-\pi) H+\pi L}\right]
$$

Then, the fraction of public officials accepting bribes is equal to $\varepsilon^{*}$ :

$$
\begin{array}{r}
\beta=\int_{0}^{\varepsilon^{*}} f(\varepsilon) d \varepsilon=\varepsilon^{*}=\theta\left[\frac{K-2 q G-C_{c}}{(1-\pi) H+\pi L}\right]= \\
\theta\left[\frac{K-2 q G-\frac{\mu}{\theta}((1-\gamma) H+\gamma L)}{(1-\pi) H+\pi L}\right]
\end{array}
$$

where $\frac{\partial \beta}{\partial q}<0$ and $\frac{\partial \beta}{\partial G}<0$ indicate that the higher the probability of being detected, or the higher the size of the fine, the lower the willingness to accept bribes, $\frac{\partial \beta}{\partial \pi}>0$. This suggests that the higher the probability that the public official is particularist, the higher the probability that he will accept bribes. Finally, $\frac{\partial \beta}{\partial \theta}>0$ indicates that the more widespread corruption, the higher the probability of accepting a bribe.

\subsection{The Citizen's Decision}

Given the public official's incentives, citizens internalize the probability $\beta$ that a bribe is accepted and choose whether to offer a bribe or not. Since matchings are randomly determined, and the sensitivity of the public official to the social norm cannot be observed ex ante, citizens do not know the exact size of the bribe before the bargain takes place. However, citizens recognize that collusion can occur if and only if the public official's sensitivity to the social norm is sufficiently small $\left(0<\varepsilon<\varepsilon^{*}\right)$. Thus, based on equations (8) and (2), the expected bribery amount $E(B)$, under the condition $0<\varepsilon<\varepsilon^{*}$, is

$$
E(B)=\frac{1}{2}\left[K+C_{c}+\frac{1}{\theta} E\left(\varepsilon \mid 0<\varepsilon<\varepsilon^{*}\right)((1-\pi) H+\pi L)\right]
$$

with $E\left(\varepsilon \mid 0<\varepsilon<\varepsilon^{*}\right)=\frac{\varepsilon^{*}}{2}$ given the assumption that $\varepsilon$ has a uniform distribution. Using equations (8) and (11), the expected bribery amount is equal to

$$
E(B)=\frac{3}{4} K-\frac{3}{4} C_{c}-\frac{1}{2} q G .
$$


A citizen will offer a bribe as long as

$$
\begin{gathered}
\gamma\left[(1-\beta)\left(Y_{c}\right)+\beta\left(Y_{c}+K-L \frac{\mu}{\theta}-B-q G\right)-Y_{c}\right]+ \\
(1-\gamma)\left[(1-\beta)\left(Y_{c}\right)+\beta\left(Y_{c}+K-H \frac{\mu}{\theta}-B-q G\right)-Y_{c}\right]>0
\end{gathered}
$$

i.e.

$$
K-E(B)-q G-\frac{\mu}{\theta}[(1-\gamma) H+\gamma L]>0
$$

Using (13) in (15), given equation (2), we can find the value $\mu^{*}$ that makes the citizen indifferent between engaging in bribery or not:

$$
\mu^{*}=\theta\left[\frac{K-2 q G}{(1-\gamma) H+\gamma L}\right]
$$

As above, given the uniform distribution of $\mu$, we obtain:

$$
\alpha=\int_{0}^{\mu^{*}} f(\mu) d \mu=\mu^{*}=\theta\left[\frac{K-2 q G}{(1-\gamma) H+\gamma L}\right]
$$

where $\frac{\partial \alpha}{\partial \gamma}>0, \frac{\partial \alpha}{\partial q}<0, \frac{\partial \alpha}{\partial G}<0$ and $\frac{\partial \alpha}{\partial \theta}>0$. These partial effects indicate that the higher the probability of being detected, or the higher the size of the fine, the lower the probability that the citizen offers a bribe; the higher the probability that the citizen is particularist, or the higher the perception of widespread corruption, the higher the probability that the citizen offers a bribe.

The model also provides explicit predictions on how the effect of particularism on offering a bribe is affected by aggregate variables, such as the overall diffusion of corruption, the level of deterrence and the pervasiveness of particularism. Taking the partial derivative of (17) with respect to $\gamma$, we obtain

$$
\frac{\partial \alpha}{\partial \gamma}=\theta(H-L) \frac{K-2 q G}{[(1-\gamma) H+\gamma L]^{2}}
$$

The expression in (18) indicates that the effect of individual particularism on the probability to offer a bribe is higher when corruption is more widespread $\left(\frac{\partial^{2} \alpha}{\partial \gamma \partial \theta}>0\right)$. When corruption is widespread, the social stigma associated with this behavior is smaller, so that the cost of offering a bribe is lower. Since the effects of individual particularism and overall corruption are complements, being particularist has a stronger effect on bribe offering in countries where corruption is more widespread. From (18) it can also be shown that $\frac{\partial^{2} \alpha}{\partial \gamma \partial G}<0$ and $\frac{\partial^{2} \alpha}{\partial \gamma \partial q}<0$, indicating that the effect of particularism on bribe offering is smaller in countries where deterrence is stronger. Furthermore, $\frac{\partial^{2} \alpha}{\partial \gamma^{2}}=-2(L-H)(H-L) \theta \frac{K-2 q G}{[(1-\gamma) H+\gamma L]^{3}}>0$, indicating that the effect of particularism on the decision to offer a bribe is higher the higher the fraction of particularists in the society. 


\subsection{Reversing the game}

It is possible to consider cases where it is the public official who asks the citizen for a bribe, rather than the citizen offering a bribe to the public official. The model presented above can be easily adapted to describe such transactions. In the first stage, the public official internalizes the possibility for collusion with the citizen and evaluates the costs and benefits of corruption. As above, given that the matching between a citizen and a public official is isolated and random, the probability of successful collusion faced by a public official is given by the fraction of collaborative citizens $(\beta)$. The public official internalizes this success rate in his decision, and decides whether or not to ask for a bribe. In the second stage, the citizen decides whether or not to accept the public official's proposal for collusion. In the third stage, the bribe amount $B$ is determined by bargaining between the citizen and the public official.

Solving the game as above, and keeping the same notation, the probability that the citizen accepts to collude and, therefore, the probability of being asked for a bribe, is

$$
\beta=\theta\left[\frac{K-2 q G-\frac{\varepsilon}{\theta}(L \pi+(1-\pi) H)}{(1-\gamma) H+\gamma L}\right] .
$$

The probability that the citizen is asked for a bribe is equal to:

$$
\alpha=\theta\left[\frac{K-2 q G}{\pi L+(1-\pi) H}\right]
$$

As above, $\alpha$ depends on the public official's particularism, on the citizen's gross gain from corruption and on the expected sanction. It does not depend on the citizen's particularism.

\section{Data and Methods}

Our empirical analysis is based on the second round of the European Social Survey (ESS), covering 49,066 individuals in 26 nations for the period 20042006. The questionnaire in the ESS included, among others, questions on family status, employment, well-being, health and economic morality. Three main questions on bribery were included in the questionnaire. The first is whether respondents have offered a bribe ("How often, if ever, have you offered a favor or bribe to a public official in return for their services in the last five years?"). The second is whether respondents have been asked for a bribe ("How often, if ever, a public official asked you for a favor or a bribe in return for a service in the last five years?"). The responses are coded as never $=1$, once $=2$, twice $=3$, three of four times $=4$ and five times or more $=5$. For ease of interpretation, we re-coded these two variables into 
binary outcomes with "ever offered/been asked for bribes" equal to 1 and "never" equal to 0. The third question is about bribe justification ("How wrong is that a public official asks someone for a favor or bribe in return for their services?"), with responses coded as: seriously wrong $=1$, wrong $=2$, a bit wrong $=3$, and not wrong at all $=4$. For the 25 countries in the sample (observations for Ukraine were excluded due to major data quality problems), 1.7 per cent of the individuals in the sample report to have offered a bribe and about 4 per cent to have been asked for a bribe. There is substantial variability across countries, with Finland displaying the lowest fraction of people declaring to have offered or been asked for a bribe $(0.15$ per cent and 0.90, respectively) and Slovakia the highest (7.8 per cent and 14.3 per cent, respectively).

We measured particularism on the basis of the difference between, on the one hand, how important it is to be loyal to friends and devote to people close, and, on the other hand, how important it is to follow rules. In addition, since particularists belong to closed (bonding) networks, we proxied this aspect empirically with questions about openness to migration. ${ }^{8}$ Overall, in our analysis an individual is defined particularist if (a) the difference between the importance attributed to the loyalty towards the inner circle and the need to follow general rules, and (b) the sum of the answers to the questions about openness to migration, are both above the 75th percentile of the sample. This indicator of particularism is thus based on both the definition by Parsons and Shils (1951) and a proxy of bonding network, a key feature of particularism (Uslaner, 2002).

In our empirical specifications, we included among control variables the respondent's subjective evaluations of political interest, trust, religion and family income (Dong and Torgler, 2009, Torgler and Valev, 2010, Guerrero and Rodriguez-Oreggia, 2008). The estimated specifications also include a variable accounting for individual honesty ("How much do you agree or disagree with this statement: If you want to make money, you cannot always act honestly") and a variable accounting for the importance of being admired ("Now I will briefly describe some people. Please listen to each description and tell me how much each person is or is not like you. It's important to her/him to show her/his abilities. She/he wants people to admire what she/he does.") in order to control for systematic effects of social desirability. Moreover, in order to take into account the networks of relations that can favor collusive bribery, we included among the regressors a variable measuring the number of friends that can support the respondent in case of illegal activities. $^{9}$

In two specifications of our model, we also accounted for the percep-

8 "To what extent do you think that your country should allow people of (1) the same or (2) different race or ethnic group as the majority to live in the country?"

9 "Suppose you planned to get benefits or services you were not entitled to. How many of your friends or relatives do you think you could ask for support?." 
tion of overall corruption by including an aggregate measure of the level of overall corruption, the Corruption Perception Index (CPI, Transparency International, 2004), or a variable measuring the fraction of individuals that in each country declared to have actually offered a bribe (Corruption Diffusion). Furthermore, in order to account for the government's ability to deter corruption and for the perception of the extent to which public power is exercised for private gain, we also added an aggregate measure of the Worldwide Governance Indicators of the World Bank (Control of Corruption). Table 1 presents descriptive statistics for all the variables used in the econometric analysis.

Table 1: Descriptive statistics

\begin{tabular}{|c|c|c|c|c|c|}
\hline Variable & Mean & Std. Dev. & Min. & Max. & $\mathbf{N}$ \\
\hline Offered bribe & 0.02 & 0.13 & 0 & 1 & 45503 \\
\hline Was asked for bribe & 0.05 & 0.21 & 0 & 1 & 43074 \\
\hline Bribe wrong & 3.65 & 0.59 & 1 & 4 & 45419 \\
\hline Particularism & 0.1 & 0.3 & 0 & 1 & 46955 \\
\hline Particularism2 & 0.25 & 0.44 & 0 & 1 & 46955 \\
\hline Particularism3 & 0.1 & 0.3 & 0 & 1 & 43405 \\
\hline Age & 46.48 & 18.4 & 13 & 102 & 46714 \\
\hline Gender & 0.46 & 0.5 & 0 & 1 & 46955 \\
\hline Education & 11.5 & 4.07 & 0 & 44 & 46398 \\
\hline Married & 0.53 & 0.5 & 0 & 1 & 44941 \\
\hline Household members & 2.87 & 1.5 & 1 & 18 & 46926 \\
\hline Income & 2.02 & 0.86 & 1 & 4 & 44418 \\
\hline Minority ethnic group & 0.04 & 0.2 & 0 & 1 & 46015 \\
\hline Immigrant & 0.06 & 0.24 & 0 & 1 & 46585 \\
\hline Son of immigrants & 0.02 & 0.15 & 0 & 1 & 46585 \\
\hline Big city & 0.2 & 0.4 & 0 & 1 & 46846 \\
\hline Suburbs big city & 0.12 & 0.33 & 0 & 1 & 46846 \\
\hline Town & 0.32 & 0.46 & 0 & 1 & 46846 \\
\hline Obey law & 2.31 & 0.93 & 1 & 5 & 45251 \\
\hline Friends support & 1.6 & 0.76 & 1 & 4 & 35532 \\
\hline Trust & 5.92 & 2.48 & 0 & 10 & 46762 \\
\hline Trust legal system & 6.18 & 2.62 & 0 & 10 & 45567 \\
\hline Trust public officials & 3.21 & 0.92 & 1 & 5 & 44038 \\
\hline Religiosity & 5.89 & 2.99 & 0 & 10 & 46624 \\
\hline Admired & 3.23 & 1.38 & 1 & 6 & 43876 \\
\hline Control of Corruption & 1.4 & 0.85 & -0.33 & 2.59 & 46955 \\
\hline CPI & 6.73 & 2.03 & 3.2 & 9.70 & 46955 \\
\hline Corruption Diffusion & 35.1 & 49.70 & 1 & 203 & 46955 \\
\hline
\end{tabular}

Source: European Social Survey, 2004-2006. See Section 4 for a description of the variables. 
In order to assess the robustness of our definition of particularism, we also considered two alternative indicators. The first (particularism2) was constructed using an additive model for the four main variables (how important it is to be loyal to friends and devote to people close, minus how important it is to follow rules, plus the two variables on closure towards migration described above). In this case, an individual is defined particularist if the resulting indicator is greater then the 75 th percentile of the sample. The second alternative indicator (particularism3) defines an individual as particularist if the difference between how important it is to be loyal to friends and devote to people close and how important it is to follow rules is greater then the 75th percentile of the sample. We compared our alternative proxies for particularism with different measures of universalism. ${ }^{10}$ Table 2 reports the results. The three indicators of particularism are positively and significantly correlated pair-wise among them and negatively and significantly correlated with the indicators of universalism. This indicates that our measure of particularism is qualitatively robust to alternative definitions. In the following, we thus focus on the variable particularism as the key explanatory variable, while also considering particularism2 and particularism3 for checking the robustness of the results.

Table 2: Correlations between indicators of particularism and universalism

\begin{tabular}{lcccc}
\hline \hline & Particularism & Particularism2 & Particularism3 & Obey law \\
\hline Particularism2 & $0.47^{* * *}$ & & & \\
Particularism3 & $0.74^{* * *}$ & $0.29^{* * *}$ & & \\
Obey law & $-0.04^{* * *}$ & $-0.09^{* * *}$ & $-0.05^{* * *}$ & \\
Trust & $-0.07^{* * *}$ & $-0.13^{* * *}$ & $-0.05^{* * *}$ & -0.00 \\
\hline
\end{tabular}

Source: European Social Survey, 2004-2006. See Section 4 for a description of the variables. ${ }^{*}$ denotes significance at 0.10 level $\left(* *\right.$ at $0.05,{ }^{* * *}$ at 0.01$)$.

The theoretical model presented in Section 3 provides a number of relevant testable predictions. First, at the individual level, being particularist increases the probability of offering a bribe, while it does not affect the probability of being asked for a bribe. Second, at the aggregate level, corruption deterrence decreases the probability of offering and being asked for a bribe, while the pervasiveness of corruption increase the probability of offering and being asked for a bribe. Third, focusing on moderating factors, the effect of individual particularism on the probability to offer a bribe is higher in countries where corruption or particularism are more widespread, while it is lower in countries where corruption deterrence is stronger.

\footnotetext{
${ }^{10}$ As for trust, we considered the standard question "Generally speaking, would you say that most people can be trusted?", while respect for general laws was proxied by the answer to the question: "How much do you agree or disagree with this statement about how people see rules and laws: You should always strictly obey the law even if it means missing good opportunities".
} 
In order to test these hypotheses, we use several econometric techniques. We start by estimating separate probit models for each of the two dependent variables (having offered a bribe and having been asked for a bribe, respectively). We focus on the effect of particularism, while controlling for a wide set of control variables, at both individual and country level. Standard errors are clustered by country, in order to take into account the nested structure of the data (individual level within country level), and the use of aggregate variables in a micro-level specification.

Next, in order to take into account the possible endogeneity of our key explanatory variable, we estimate the effect of particularism on the probability of offering a bribe by using an Instrumental Variables (IV) estimator. Taking into account the binary nature of the endogenous regressor, we estimate a bivariate marginal effect probit model consisting of two specifications, a reduced form equation for the potentially endogenous dummy of particularism and a structural form equation determining the outcome of interest. We included two instruments in the reduced form equation. The first is based on a question about how important it is for respondents to care for nature and environment. We assume that nature and environment are public goods and that particularist individuals, who have a smaller concern for general interest, care less for them. The second instrument is based on a question regarding whether European unification should go further or whether it has gone too far. As in Uslaner and Conley (2003), we assume that particularist individuals, who associate primarily with people of their own kind, tend to support institutions defending national interests, whereas universalist individuals with looser ties are more likely to support institutions overcoming national interests.

As an additional way of addressing the potential endogeneity of particularism, we present results obtained by using Propensity Score (PS) matching estimators (Rosenbaum and Rubin, 1983). These are obtained by using either the nearest neighbor method, which selects the comparison units whose propensity scores are closest to the treated unit in question, or the kernel method, whereby every treated subject is matched with the weighted average of the control subjects, with weights being inversely proportional to the distance between the treated and the control group's propensity scores.

Finally, in order to investigate the underlying causal mechanism, based on the effect of particularism on the psychological cost of bribing, we estimate a structural model with three equations having as dependent variables particularism, the cost of bribing, and the probability of offering a bribe, respectively. In the first equation, the probability of being particularist is explained by a set of individual characteristics, including age, gender, education, income, family structure, employment, immigration and minority status. In the second equation, the cost of bribing is modeled as a function of particularism, the set of exogenous variables described above, Control of Corruption and CPI. In the third equation, offering a bribe is explained by 
the cost of bribing, particularism, and the same set of individual-level and aggregate control variables.

\section{Results}

This section presents the results of the empirical analysis. We start by estimating univariate probit models to measure the effect of particularism on the probability of offering and being asked for a bribe, respectively. We then present the results of Instrumental Variables and Propensity Score estimation. Finally, we turn to a structural equation model to explicitly address the simultaneous relationship between particularism, the psychological cost of bribing and the decision to offer a bribe.

\subsection{The Determinants of Bribing}

Table 3 reports probit estimation results (marginal effects) for the determinants of the decision to offer a bribe. We consider five different specifications, with progressively larger sets of control variables. ${ }^{11}$ The first specification includes only standard socio-demographic characteristics, such as age, years of schooling, gender, marital and employment status, household's composition, income and minority status. Model (2) also accounts for immigration status and living context, as well as network characteristics and political interest. Model (3) also includes variables related to trust (both general and institutional) and religiosity. Models (4) and (5) include alternative indicators of the pervasiveness of corruption. Except for these last two models, all specifications also include country dummies.

Consistent with the theoretical predictions, particularism has a positive and significant effect on the probability of offering a bribe in all specifications. Across the five different specifications, the size of the coefficient is virtually unchanged. The size of the effect is small in absolute terms (0.4 to 0.3 percentage points), similarly to related studies based on micro data (e.g., Mocan, 2008, Lee and Guven, 2013), reflecting the fact that offering a bribe has a very small frequency in the sample (about 1.6 per cent). ${ }^{12}$ In relative terms, however, the size of the effect of particularism, is comparable to, or larger than, that of gender or employment status. We examined the robustness of the results to the use of alternative definitions of particularism,

\footnotetext{
${ }^{11}$ It should be observed that the use of larger sets of control variables reduces the number of observations. However, it allows us to obtain a more complete characterization of the determinants of the decision to engage in corruption.

${ }^{12}$ The large size of our sample allows us to rule out the possible bias arising from the fact that our binary dependent variable describes a rare event (e.g., King and Zeng, 2001). Indeed, using a penalized maximum likelihood regression approach (Firth, 1993), the results are virtually unchanged.
} 
as described in Section 4. The key result of the positive effect of particularism on the decision to offer a bribe is robust to the use of alternative definitions. ${ }^{13}$

Focusing on aggregate variables, higher levels of perceived corruption (i.e. a lower CPI or a higher Corruption Perception) are associated to a significantly higher probability of offering a bribe. Stronger corruption deterrence (i.e., a higher Control of Corruption) is negatively related to the probability of offering a bribe, although not significantly. Turning to individual characteristics, in line with the literature, institutional trust (in the legal system and in public officials) is associated with a significantly lower probability of offering a bribe. Being an immigrant or a son of an immigrant is not significantly related to the probability of offering a bribe. As expected, being more honest is associated with a significantly lower probability of offering a bribe, while having a large number of friends supporting illegal activities is associated with a significantly higher probability of offering a bribe (RoseAckerman, 2001). As for gender, we find that, consistent with the literature (e.g., Lee and Guven, 2013), males are significantly more likely to offer a bribe than females.

Table 4 reports probit estimates (marginal effects) for the determinants of being asked for a bribe, using the same set of specifications and control variables as for the probability of offering a bribe. Overall, we find no significant relation between particularism and being asked for a bribe. This is consistent with the view that particularism is private information of the bribee and cannot be observed ex ante, so that interactions take place as if citizen-public official pairs were formed randomly.

Table 5 reports the results of estimating model (5) in Table 3 , while adding interaction terms between particularism and a number of country-specific factors: CPI, control of corruption, corruption diffusion and the fraction of particularists. As shown in Section 3, the first two interaction terms are predicted to be negative (i.e., higher corruption deterrence and lower perceived corruption are associated with a lower effect of particularism on the probability to offer a bribe), while the other two interaction terms are expected to be positive. Empirically, all the estimated interaction terms have the expected sign. While the interactions for $\mathrm{CPI}$ and $\mathrm{CoC}$ are not significant, the interaction terms for overall particularism and pervasiveness of corruption are both statistically significant.

\subsection{Accounting for Endogeneity}

Table 6 reports IV estimation results. The instrumental variables are jointly and individually significantly related to corruption. In addition, the validity of the instruments is not rejected by a Sargan test of over-identifying restrictions $\left(\chi_{2}^{2}=0.055, p=0.814\right)$. The IV estimate of the effect of particularism

\footnotetext{
${ }^{13}$ The estimated coefficient for particularism2 and particularism3 is $0.001(p<0.10)$ and $0.004(p<0.05)$, respectively.
} 
Table 3: Determinants of offering a bribe, probit estimates

\begin{tabular}{|c|c|c|c|c|c|}
\hline & $(1)$ & $(2)$ & $(3)$ & $(4)$ & $(5)$ \\
\hline Particularism (d) & $0.004^{* *}$ & $0.003^{* *}$ & $0.003^{* *}$ & $0.004^{*}$ & $0.004^{*}$ \\
\hline Age & 0.000 & 0.000 & 0.000 & 0.000 & 0.000 \\
\hline Age Squared & -0.000 & -0.000 & -0.000 & -0.000 & -0.000 \\
\hline Male (d) & $0.004^{* * *}$ & $0.003^{* *}$ & $0.002^{* *}$ & $0.003^{* * *}$ & $0.002^{*}$ \\
\hline Education & 0.000 & 0.000 & 0.000 & 0.000 & $0.000^{* *}$ \\
\hline Employed (d) & $-0.003^{* * *}$ & $-0.003^{* * *}$ & $-0.003^{* * *}$ & $-0.004^{* * *}$ & $-0.004^{* * *}$ \\
\hline Married (d) & -0.000 & -0.001 & -0.001 & -0.001 & -0.001 \\
\hline HH's Memebers & -0.000 & -0.000 & -0.000 & 0.000 & -0.000 \\
\hline Income & 0.000 & 0.000 & -0.000 & 0.001 & 0.000 \\
\hline Minority ethnic group & $-0.005^{* *}$ & $-0.006^{* *}$ & $-0.005^{* *}$ & $-0.006^{* *}$ & $-0.005^{*}$ \\
\hline Immigrant (d) & & 0.003 & 0.003 & 0.001 & 0.004 \\
\hline Son of immigrants (d) & & 0.002 & 0.001 & -0.001 & 0.001 \\
\hline Big City (d) & & 0.002 & 0.002 & $0.003^{*}$ & 0.000 \\
\hline Suburbs Big City (d) & & 0.002 & 0.001 & 0.001 & 0.000 \\
\hline Village $(\mathrm{d})$ & & 0.001 & 0.001 & 0.001 & 0.002 \\
\hline Obey law & & $-0.003^{* * *}$ & $-0.003^{* * *}$ & $-0.003^{* * *}$ & $-0.003^{* * *}$ \\
\hline Friends support & & $0.005^{* * *}$ & $0.005^{* * *}$ & $0.006^{* * *}$ & $0.006^{* * *}$ \\
\hline Political Interest & & -0.001 & -0.001 & -0.001 & -0.001 \\
\hline Admired & & -0.000 & -0.000 & -0.001 & 0.000 \\
\hline Trust & & & 0.000 & -0.000 & 0.000 \\
\hline Trust legal system & & & -0.000 & $-0.001^{* *}$ & $-0.001^{* *}$ \\
\hline Trust public officials & & & $-0.003^{* * *}$ & $-0.003^{* * *}$ & $-0.003^{* * *}$ \\
\hline Religiosity & & & $0.000^{* *}$ & $0.001^{* * *}$ & 0.000 \\
\hline Corruption Diffusion & & & & $0.000^{* * *}$ & \\
\hline Control of Corruption & & & & & -0.001 \\
\hline CPI & & & & & $-0.004^{* *}$ \\
\hline \multicolumn{6}{|l|}{ Constant } \\
\hline Observations & 37275 & 28410 & 27110 & 27535 & 27535 \\
\hline Country dummies & $\mathrm{X}$ & $\mathrm{X}$ & $\mathrm{X}$ & & \\
\hline
\end{tabular}


Table 4: Determinants of being asked for a bribe, probit estimates

\begin{tabular}{|c|c|c|c|c|c|}
\hline & $(1)$ & $(2)$ & $(3)$ & $(4)$ & $(5)$ \\
\hline Particularism (d) & 0.003 & 0.002 & 0.001 & 0.002 & 0.002 \\
\hline Age & $0.001^{* *}$ & $0.001^{* *}$ & 0.001 & 0.000 & 0.000 \\
\hline Age Squared & $-0.000^{* * *}$ & $-0.000^{* * *}$ & $-0.000^{* *}$ & $-0.000^{*}$ & $-0.000^{* *}$ \\
\hline Male (d) & $0.015^{* * *}$ & $0.011^{* * *}$ & $0.009^{* * *}$ & $0.012^{* * *}$ & $0.009^{* * *}$ \\
\hline Education & $0.002^{* * *}$ & $0.001^{* * *}$ & $0.001^{* * *}$ & $0.001^{*}$ & $0.001^{* * *}$ \\
\hline Employed (d) & -0.003 & -0.004 & $-0.004^{*}$ & -0.004 & $-0.005^{* *}$ \\
\hline Married (d) & 0.002 & $0.004^{* *}$ & $0.005^{* *}$ & $0.007^{* * *}$ & $0.005^{* *}$ \\
\hline Household's Members & -0.002 & -0.001 & -0.001 & 0.000 & -0.001 \\
\hline Income & $0.007^{* * *}$ & $0.009^{* * *}$ & $0.006^{* * *}$ & $0.010^{* * *}$ & $0.007^{* * *}$ \\
\hline Minority ethnic group & $-0.013^{* * *}$ & $-0.008^{*}$ & -0.005 & -0.005 & -0.005 \\
\hline Immigrant (d) & & 0.005 & $0.007^{*}$ & 0.005 & $0.014^{*}$ \\
\hline Son of immigrants (d) & & -0.001 & -0.001 & -0.003 & 0.003 \\
\hline Big City (d) & & $0.008^{* *}$ & $0.007^{* *}$ & $0.019^{* * *}$ & $0.009^{* *}$ \\
\hline Suburbs Big City (d) & & 0.003 & 0.002 & 0.004 & 0.002 \\
\hline Village (d) & & -0.005 & -0.003 & -0.003 & -0.003 \\
\hline Obey law & & $-0.006^{* * *}$ & $-0.004^{* * *}$ & $-0.003^{* *}$ & $-0.004^{* * *}$ \\
\hline Friends support & & $0.010^{* * *}$ & $0.009^{* * *}$ & $0.010^{* * *}$ & $0.010^{* * *}$ \\
\hline Political Interest & & $-0.005^{* * *}$ & $-0.005^{* * *}$ & $-0.006^{* * *}$ & $-0.005^{* * *}$ \\
\hline Admired & & $-0.003^{* * *}$ & $-0.002^{* * *}$ & $-0.004^{* * *}$ & $-0.002^{* *}$ \\
\hline Trust & & & -0.001 & $-0.002^{* * *}$ & -0.001 \\
\hline Trust legal system & & & $-0.001^{*}$ & -0.001 & -0.000 \\
\hline Trust public officials & & & $-0.014^{* * *}$ & $-0.016^{* * *}$ & $-0.015^{* * *}$ \\
\hline Religiosity & & & 0.000 & $0.002^{* * *}$ & 0.000 \\
\hline Corruption Diffusion & & & & $0.000^{* * *}$ & \\
\hline Control of Corruption & & & & & 0.008 \\
\hline CPI & & & & & $-0.014^{* *}$ \\
\hline \multicolumn{6}{|l|}{ Constant } \\
\hline Observations & 35394 & 27709 & 26730 & 26730 & 26730 \\
\hline Country dummies & $\mathrm{X}$ & $\mathrm{X}$ & $\mathrm{X}$ & & \\
\hline
\end{tabular}

Note: probit estimates (marginal effects). Dependent variable: binary variable for having being asked for a bribe. (d) indicates discrete change of dummy variable from 0 to 1 . Standard errors clustered by country. ${ }^{*}$ denotes significance at 0.10 level $\left(* *\right.$ at $0.05,{ }^{* * *}$ at 0.01$)$.

Table 5: Determinants of offering a bribe, interactions with particularism

\begin{tabular}{lcccc}
\hline \hline & $(1)$ & $(2)$ & $(3)$ & $(4)$ \\
\hline Interaction with: & CPI & CoC & Mean Particularism & Corruption Diffusion \\
\hline & $-0.002)$ & -0.006 & $0.03^{* * *}$ & $0.002^{* * *}$ \\
& $(0.001)$ & $(0.003)$ & $(0.147)$ & $(0.000)$ \\
\hline
\end{tabular}

Note: probit estimates (marginal effects). Dependent variable: binary variable for having offered a bribe. CPI: Corruption Perception Index. CoC: Control of Corruption.

Number of observations: 27807. Standard errors (clustered by country) reported in brackets. ${ }^{*}$ denotes significance at 0.10 level $\left(* *\right.$ at $0.05,{ }^{* * *}$ at 0.01$)$. 
on the probability of offering a bribe is positive and significant. Indeed, the size of the estimated effect is larger when using IV, suggesting that failing to account for the endogeneity of particularism may lead to underestimate its effect on the propensity to offer a bribe. This would be the case if for example, as it is reasonable to expect, risk aversion has a positive effect on particularism and a negative effect on the propensity to offer a bribe.

Table 6: Instrumental Variables estimation results

\begin{tabular}{|c|c|c|}
\hline & $\begin{array}{c}\text { Particularism } \\
\text { (First stage) }\end{array}$ & $\begin{array}{c}\text { Offered bribe } \\
\text { (Second stage) }\end{array}$ \\
\hline Particularism (d) & & $0.013^{* * *}$ \\
\hline Age & 0.001 & 0.000 \\
\hline Age Squared & 0.000 & -0.000 \\
\hline Gender (d) & 0.004 & 0.001 \\
\hline Education & $-0.002^{* * *}$ & $0.001^{* * *}$ \\
\hline Employed (d) & 0.001 & $-0.004^{* * *}$ \\
\hline Married (d) & 0.002 & -0.002 \\
\hline HH's Memebers & -0.001 & -0.000 \\
\hline Income & $0.006^{* * *}$ & -0.001 \\
\hline Minority ethnic group & 0.005 & $-0.005^{* *}$ \\
\hline Immigrant (d) & -0.000 & 0.003 \\
\hline Son of immigrants (d) & -0.010 & 0.004 \\
\hline Big City (d) & -0.003 & 0.001 \\
\hline Suburbs Big City (d) & -0.004 & 0.001 \\
\hline Village $(d)$ & 0.003 & 0.002 \\
\hline Obey law & $-0.006^{* * *}$ & $-0.004^{* * *}$ \\
\hline Friends support & -0.002 & $0.006^{* * *}$ \\
\hline Political Interest & $0.007^{* * *}$ & $-0.002^{* * *}$ \\
\hline Admired & 0.001 & -0.000 \\
\hline Trust & $-0.002^{* * *}$ & $0.001^{* * *}$ \\
\hline Trust legal system & 0.000 & $-0.001^{* * *}$ \\
\hline Trust public officials & -0.001 & $-0.003^{* * *}$ \\
\hline Religiosity & 0.000 & 0.000 \\
\hline Control of Corruption & -0.026 & $0.004^{*}$ \\
\hline CPI & 0.007 & $-0.006^{* * *}$ \\
\hline European Unification & $-0.002^{* * *}$ & \\
\hline Important to care for nature & $-0.013^{* * *}$ & \\
\hline Observations & 26170 & 26693 \\
\hline
\end{tabular}

As an additional way of addressing the potential endogeneity of particularism, we estimated our model by using propensity score matching. The 
propensity scores were computed considering variables affecting both treatment and outcome (Heckman et al., 1999), fixed over time, and found to be relevant in previous research. Moreover, following Bryson et al. (2002), we preferred to estimate a conservative model with a short list of covariates. More specifically, the first estimated propensity score is based on religiosity, gender and education. The second also adds immigrant status, while the third considers gender, education and minority status. The three propensity scores are calculated by restricting the analysis of the balancing property to all treated plus those controls in the region of common support. ${ }^{14}$ Furthermore, in order to assess the robustness of the estimates, we considered two alternative methods to compute average treatment on the treated (ATT): the Nearest-Neighbor method, where all treated units find a match, and the Kernel Matching, where all treated are matched with a weighted average of all controls in order to correct for the possibility of poor matching. In both cases, the computation of the ATT was restricted to the region of common support.

Table 7 reports PS estimation results. The coefficient for particularism is positive and significant, and virtually unchanged, across all specifications and very close to the one obtained by using Instrumental Variables. Overall, we conclude that the findings are robust to the use of alternative estimation techniques, and the relationship between particularism and corruption can be given a causal interpretation.

Table 7: Propensity score matching estimation results

\begin{tabular}{ccccccc}
\hline \hline & \multicolumn{3}{c}{ Nearest Neighbor } & \multicolumn{3}{c}{ Kernel } \\
\hline & PS 1 & PS 2 & PS 3 & PS 1 & PS 2 & PS 3 \\
\hline \multirow{2}{*}{ Particularism } & $0.010^{* * *}$ & $0.010^{* * *}$ & $0.010^{* *}$ & $0.009^{* *}$ & $0.008^{* *}$ & $0.009^{* *}$ \\
& $(0.003)$ & $(0.003)$ & $(0.004)$ & $(0.003)$ & $(0.003)$ & $(0.004)$ \\
\hline
\end{tabular}

Note: propensity score estimates. Dependent variable: binary variable for having offered a bribe. ${ }^{*}$ denotes significance at 0.10 level $\left(* *\right.$ at $0.05,{ }^{* * *}$ at 0.01$)$. Standard errors in brackets.

\subsection{The Psychological Cost of Bribing}

Table 8 reports the results of a structural equation model of corrupt behavior, aimed at further exploring the theoretical model presented in Section 3. More specifically, we estimate the parameters of the simultaneous relation between particularism, the psychological cost of bribing, and the act of offering a bribe. Our theoretical model assumes that particularism reduces the

\footnotetext{
${ }^{14}$ Common support ensures that persons with the same value of the set of observable covariates have a positive probability of being both particularist or non particularist (Heckman et al., 1999). Intuitively, this means that there is enough overlap in the distribution of particularist and non-particularist individuals.
} 
perceived cost of bribing and, through this effect, it increases the probability of offering a bribe. The results support this hypothesis. First, particularism is associated to a significantly lower perceived cost of bribing. Second, through this mechanism, particularism significantly increases the probability of offering a bribe, with an estimated effect of 0.5 percentage points. These results complement the findings in Tavits (2010), according to which individuals are more likely to engage in bribery when they do not view corruption as wrong. Our results contribute to identify the mechanism through which universalism may help to deter corruption.

Table 8: Structural Equation Model

\begin{tabular}{lccc}
\hline \hline & $(1)$ & $(2)$ & $(3)$ \\
& Particularism & Bribe cost & Offered bribe \\
\hline Particularism & & $-.050^{* * *}$ & $.005^{* * *}$ \\
& & $(0.018)$ & $(0.003)$ \\
Bribe Cost & & & $-.013^{* * *}$ \\
& & & $(0.003)$ \\
Standard Controls & $\mathrm{X}$ & $\mathrm{X}$ & $\mathrm{X}$ \\
\hline Oservations & 27427 & 27427 & 27427 \\
\hline
\end{tabular}

Note: Structural Equation Model Estimates. ${ }^{*}$ denotes significance at 0.10 level ${ }^{* *}$ at $0.05,{ }^{* * *}$ at 0.01$)$. Standard errors clustered by country reported in brackets.

\section{Conclusion}

Reducing corruption is a key policy objective throughout the world. In order to achieve this objective, it is necessary to have a better understanding of the causes of corruption. Until recently, economists have focused mainly on the macro-level determinants of corruption. Much less is known about the individual-level determinants of corruption and, in particular, about the role played by individual cultural norms.

In this paper, we analyzed theoretically and empirically the effects of the cultural norms of particularism and universalism on collusive bribery. We found that, as predicted by the theory, particularism lowers the perceived cost of corruption and, as a consequence, it has a positive causal effect on the probability of offering bribes. No significant effect of particularism was found for the probability of being asked for a bribe. Our results are robust to the use of alternative definitions of particularism, specifications of the model and econometric techniques to account for the potential endogeneity of particularism. Overall, our results indicate that decreasing particularism can be identified as an effective tool for decreasing corruption. The key question is then how to favor the development of the cultural norm of universalism as opposed to particularism. 
Several studies in social psychology show that an individual builds his own social identity on the basis of perceived membership in a social group (e.g., Tajfel and Turner, 1986). The intrinsic psychological need for a positive self-concept drives individuals to compare their own group with other groups to which they do not belong, giving preferential treatment to members relative to non-members. In this perspective, humans are naturally sectarian and particularism is a feature of human nature that may not be easily affected. Our view, as economists, is slightly different. If particularism can be considered an individual cultural norm, it can be shaped by the social, economic and political environment, albeit in a medium- to long-run perspective (Bisin and Verdier, 2001). Although it is difficult to identify specific policy actions aimed at reducing particularism and favouring universalism, as a way of combating corruption and other types of anti-social behaviors, education can be identified as the most promising area of intervention.

Our findings provide a contribution to the understanding of the determinants of corruption at individual level. However, they can also be extended to other types of illegal economic behavior. For instance, particularism can be expected to be positively related to tax evasion, since it raises the willingness to free-ride on others. Further research will have to assess the role played by particularism and universalism for other relevant types of antisocial economic behavior. 


\section{References}

Akerlof, G., 1980. A Theory of Social Custom, of Which Unemployment May Be One Consequence. Quarterly Journal of Economics, 94(4), 749-"775.

Alesina A., Glaeser F., 2004, Fighting Poverty in the US and Europe: A world of Differences, Oxford University Press, Oxford UK Rodolfo De Benedetti Lecture Series.

Barr, A., Serra. D., 2010. Corruption and culture: An experimental analysis. Journal of Public Economics, 94, 862-869.

Bisin, A., Verdier, T., 2001. Agents with imperfect empathy may survive natural selection,Economics Letters, 71(2), 277-285.

Bjørnskov, C., 2006. The multiple facets of social capital. European Journal of Political Economy, 22,22.40.

Brunetti, A., Weder, B., 2003. A free press is bad news for corruption. Journal of Public Economics, 87(7-8), 1801-1824.

Bryson, A., Dorsett, R., S. Purdon, 2002, The Use of Propensity Score Matching in the Evaluation of Labour Market Policies, Working Paper No. 4, Department for Work and Pensions.

Chang, J. J., Lai, C. C., 2002. Is the Efficiency Wage Efficient? The Social Norm and Organizational Corruption, Scandinavian Journal of Economics, 104(1), 27-47.

Davis, J. H., Ruhe, J., 2003. Perceptions of country corruption: antecedents and outcomes. Journal of Business Ethics, 43 (40), 275-88.

De Blasio, G., Scalise, D., Sestito, P., 2014. Universalism vs. particularism: a round trip from sociology to economics. Bank of Italy, Occasional Papers.

Della Porta, D., Vannucci, A., 2010. The Hidden Order of Corruption: An Institutional Approach, Ashgate: Surrey, England.

Dong, B., Torgler, B., 2009. Corruption and political interest: empirical evidence at the micro level. Journal of Interdisciplinary Economics, 21, 295-326.

Dong, B., Dulleck U., Torgler, B., 2012. Conditional corruption. Journal of Economic Psychology, 33, 609-627. 
Dollar, D., Fisman, R., Gatti, R., 2001. Are Women Really the Fairer Sex? Corruption and Women in Government. Journal of Economic Behavior and Organization, 46 (4), 423-429.

Eckel, C.C., Grossman, P.J., 2005. Managing Diversity by Creating Team Identity. Journal of Economic Behavior and Organization. 58 (3), 371-392

Fernandez, R., Fogli, A., 2009. Culture: An Empirical Investigation of Beliefs, Work, and Fertility, American Economic Journal: Macroeconomics, 1(1), 146-77.

Firth, D., 1993. Bias reduction of maximum likelihood estimates. Biometrika, $80,27-38$.

Fisman, R., Gatti, R., 2002. Decentralization and Corruption: Evidence Across Countries. Journal of Public Economics, 83 (3), 325-345.

Fong, C. M, Luttmer, E.F.P., 2011. Do fairness and race matter in generosity? Evidence from a nationally representative charity experiment, Journal of Public Economics ,95(5), 372-394.

Guerrero, M., Rodriguez-Oreggia, E., 2008. On the individual decisions to commit corruption: A methodological complement. Journal of Economic Behavior and Organization, 65, 357-372.

Guiso, L., Sapienza P., Zingales, L., 2006. Does culture affect economic outcomes?. Journal of Economic Perspectives, 20, 23- "49.

Gupta, S., Davoodi, H., Alonso-Terme, R., 2002. Does Corruption Affect Income Inequality and Poverty?, Economics of Governance,3, 23-45.

Harris, D., 2007. Bonding social capital and corruption: a cross-national Empirical analysis. Environmental Economy and Policy Research Working Papers, No 27.2007: University of Cambridge.

Heckman, J. J., Lalonde, R. and J. Smith (1999), The Economics and Econometrics of Active Labor Market Programs. In Handbook of Labor Economics, Volume III, Eds. O. Ashenfelter and D. Card (Elsevier).

Husted, B.W., 1999. Wealth, culture, and corruption. Journal of International Business Studies, 30, 339-60.

King, G., Zeng, 1., 2001. Explaining Rare Events in International Relations. International Organization, 55, 3, $693-715$.

La Porta, R., Lopez-De-Silanes, F., Shleifer, A., Vishny, R.W., 1999. The Quality of Government. Journal of Law, Economics and Organization, 15 (1), 222-279. 
Lambsdorff, J., Schramm, G. M., Taube, M., 2004, The New Institutional Economics of Corruption: Norms, Trust, and Reciprocity, Routledge, London.

Lambsdorff, J.G., 2006. Causes and consequences of corruption: what do we know from a cross-section of countries? In Rose-Ackerman, S. (Ed.), International Handbook on the Economics of Corruption. Edward Elgar, Cheltenham, UK, pp. 3-51.

Lee, W.S., Guven, C., 2013. Engaging in corruption: The influence of cultural values and contagion effects at the microlevel. Journal of Economic Psychology, 39(C), 287-300.

Lipset, S.M., Lenz, G.S., 2000. Corruption, Culture, and Markets in L.E. Harrison and S.P. Huntington, eds., Culture Matters: How Values Shape Human Progress, New York, Basic Books.

Lumby, J., 2006. International perspectives on leadership and management. Management in Education, 20(4), 7-10.

Mauro, P., 1995. Corruption and growth. Quarterly Journal of Economics 110(3), 681-712.

Mauro, P., 1997.Corruption and the Composition of Government Expenditure. Public Economics, 69, 263-79.

Mocan, N., 2008. What determines corruption? International evidence from microdata. Economic Inquiry, 46, 493-510.

Parsons, T., Shils, E.A., 1951. Toward a general theory of action. Cambridge, MA: Harvard University Press.

Putnam, R., 2000. Bowling Alone: The Collapse and Revival of American Community. New York: Simon and Schuster.

Rose-Ackerman, S., 2001. Trust, honesty and corruption: reflection on the state-building process. European Journal of Sociology, 42, 27-71.

Rosenbaum, P., Rubin D., 1983. The Central Role of the Propensity Score in Observational Studies for Causal Effects. Biometrika, 70, 41-50.

Ryvkin, D., Serra, D., 2012. How corruptible are you? Bribery under uncertainty. Journal of Economic Behavior and Organization, 81(2), 466-477.

Sabatini, F., 2008. Social Capital and the Quality of Economic Development. Kyklos, 61 (3), 466-499. 
Spector, B. I., 2005. Fighting Corruption in Developing Countries: Strategies and Analysis. Bloomfield, CT: Kumarian Press.

Svensson, J., 2003. Who must pay bribes and how much? Evidence from a cross section of firms. Quarterly Journal of Economics, 118, 207-230.

Swamy A., Knack S., Lee Y., Azfar O., 2001. Gender and corruption. Journal of Development Economics, 64 (1), 25-55.

Tabellini, G., 2010. Culture and institutions: economic development in the regions of Europe. Journal of the European Economic Association. $8(4), 677-716$.

Tajfel, H.,Turner, J. C., 1986. The social identity theory of inter-group behavior., In S. Worchel and L. W. Austin (eds.), Psychology of Intergroup Relations. Chigago: Nelson-Hall.

Tavits, M., 2010. Why do people engage in corruption? The case of Estonia. Social Forces, 88, 1257-1280.

Tonoyan, V., 2003. Corruption and Entrepreneurship : Does Trust Matter?. journal of transforming economies and societies,10(37), 2-19.

Torgler, B., 2003. Tax Morale, Rule Governed Behaviour and Trust. Constitutional Political Economy, 14, 119-140.

Torgler, B., Valev, N.T., 2006. Corruption and Age. Journal of Bioeconomics, 8, 133-145.

Torgler, B., Valev, N.T., 2010. Gender and public attitude toward corruption and tax evasion. Contemporary Economic Policy, 28, 554-568.

Transparency International, 2004. Global Corruption Report 2004. Cromwell Press.

Treisman, D., 2000. The causes of corruption: a cross-national study. Journal of Public Economics, 76, 399-457.

Treisman, D., 2007. What have we learned about the causes of corruption from ten years of cross-national empirical research? Annual Review of Political Science, 10, 211-244.

Uslaner, E. M., 2002. The Moral Foundations of Trust. New York: Cambridge University Press.

Uslaner E. M., Conley R. S., 2003. Civic engagement and particularized trust: the ties that bind people to their ethnic communities. American Politics Research, 31, 331-360. 
Uslaner, E. M., 2004. Trust and Corruption. In J. G. Lambsdorf, M. Taube, and M. Schramm (Eds.), Corruption and the New Institutional Economics. London: Routledge.

Warren, M. E., 2004. Social capital and corruption, Democracy and Society, $1(1), 16-18$. 